\title{
The protective effects of ethanolic extract of Clematis terniflora against corticosterone-induced neuronal damage via the AKT and ERK1/2 pathway
}

\author{
Yoohun Noh ${ }^{1, \#}$, Seungui Cheon ${ }^{1,2, \#}$, In Hye Kim ${ }^{1}$, Inyong Kim ${ }^{2}$, Seung-Ah Lee ${ }^{3}$, Do-Hee Kim ${ }^{3}$ E Yoonhwa Jeong ${ }^{2,4, *}$ \\ ${ }^{1}$ Famenity Biomedical Research Center, Famenity, Inc., Gwacheon 13837, ${ }^{2}$ Research Center for Industrialization of Natural Nutraceuticals, \\ Dankook University, Cheonan 31116, ${ }^{3}$ Natural Pharmaceutical R\&D Center, Naturesense, Inc., Uiwang 16006, ${ }^{4}$ Department of Food \\ Science and Nutrition, Dankook University, Cheonan 31116, Korea
}

\begin{abstract}
Chronic stress induces neuronal cell death, which can cause nervous system disorders including Parkinson's disease and Alzheimer's disease. In this study, we evaluated the neuroprotective effects of Clematis terniflora extract (CTE) against corticosterone-induced apoptosis in rat pheochromocytoma (PC12) cells, and also investigated the underlying molecular mechanisms. At concentrations of $\mathbf{3 0 0}$ and $\mathbf{5 0 0}$ $\mu \mathrm{g} / \mathrm{ml}$, CTE significantly decreased apoptotic cell death and mitochondrial damage induced by $200 \mu \mathrm{M}$ corticosterone. CTE decreased the expression levels of endoplasmic reticulum (ER) stress proteins GRP78, GADD153, and mitochondrial damage-related protein $B A D$, suggesting that it downregulates ER stress evoked by corticosterone. Furthermore, our results suggested that these protective effects were mediated by the upregulation of p-AKT and p-ERK1/2, which are involved in cell survival signaling. Collectively, our results indicate that CTE can lessen neural damage caused by chronic stress. [BMB Reports 2018; 51(8): 400-405]
\end{abstract}

\section{INTRODUCTION}

Improving quality of life has become one of the most important issues in modern society (1). Quality of life depends largely on the degree or level of stress to which a person is exposed (2). For the majority of people, various types of stress are inevitable. Stress associated with multiple social factors can cause both physical and psychological problems (3). In

${ }^{*}$ Corresponding author. Tel: +82-31-8005-3176; Fax: +82-31-80054054; E-mail: yjeong@dankook.ac.kr

${ }^{\text {"T}}$ These authors contributed equally to this work.

https://doi.org/10.5483/BMBRep.2018.51.8.099

Received 30 April 2018, Revised 23 May 2018,

Accepted 12 June 2018

Keywords: Chronic stress, Clematis terniflora, Corticosterone, ER stress, Neuroprotective effect particular, chronic stress induces the destruction of neurons in the central nervous system (4), thereby causing or exacerbating a wide range of nervous system disorders including: depression (5), anxiety disorder (6), Parkinson's disease (7), and Alzheimer's disease (8). Accordingly, significant research efforts are devoted to finding ways to prevent nervous system damage by chronic stress. Recently, a benzodiazepine drug was developed and used for the treatment of stress-associated nervous system disorders (9). However, most drugs of this class are unsuitable for long-term use due to the high risk of addiction (10). In addition, these drugs can also cause a number of side effects, including drowsiness, poor concentration, ataxia, dysarthria, motor incoordination, muscle weakness, vertigo, and mental confusion (11). Consequently, the focus of research has shifted toward identifying naturally derived substances that protect neurons against the harmful effects of stress, lack serious side effects, and are safe for long-term use.

Clematis terniflora, a plant in family Ranunculaceae, is native to East Asia, Europe, and North Africa. In traditional Chinese medicine, it is used to treat tonsillitis, rheumatoid arthritis, and prostatitis (12). Consistent with these uses, the medicinal properties of $C$. terniflora include anti-nociceptive and anti-inflammatory activities (13). However, its anti-stress effects and neuroprotective functions have not been extensively studied.

In this study, we evaluated the neuroprotective effect of Clematis terniflora extract (CTE) and investigated its underlying mechanism. We used an experimental model of neuronal stress in which we applied corticosterone (14), a glucocorticoid that is secreted in response to stress, to rat pheochromocytoma (PC12) cells, which express high levels of glucocorticoid receptors.

\section{RESULTS}

Effects of corticosterone and CTE on PC12 cells

To assess the effect of corticosterone and CTE on PC12 cells, we measured the rates of cell survival and proliferation 
following drug treatment. Survival decreased over time in a concentration-dependent manner following corticosterone treatment at a concentration of $50,100,200,400$, or $800 \mu \mathrm{M}$ for 12,24 , or 48 hours (Fig. 1A). Treatment with $200 \mu \mathrm{M}$ corticosterone for 24 hours decreased survival $\sim 50 \%$ relative to untreated controls. In subsequent experiments, we used these conditions to induce cell death.

Treatment with CTE at various concentrations $(100,300$, 500 , or $1,000 \mu \mathrm{g} / \mathrm{ml}$ ) for 24 hours increased cell proliferation in a concentration-dependent manner (Fig. 1B). Thus, CTE had no intrinsic toxic effect on PC12 cells, and in fact improved at least one aspect of cellular health meaning growth.

\section{Effects of CTE on corticosterone-induced cytotoxicity in PC12} cells

To assess the neuroprotective effects of CTE against corticosterone-induced death of PC12 cells, we treated cells with both compounds and measured cell survival. As noted above, cell survival decreased by $\sim 50 \%$ after 24 hours of treatment with $200 \mu \mathrm{M}$ corticosterone. When these cells were treated with $100,300,500$, or $1,000 \mu \mathrm{g} / \mathrm{ml} \mathrm{CTE}$, survival increased in a concentration-dependent manner by $53 \%, 66 \%$, $96 \%$, and $113 \%$, respectively (Fig. 1C). These findings suggest
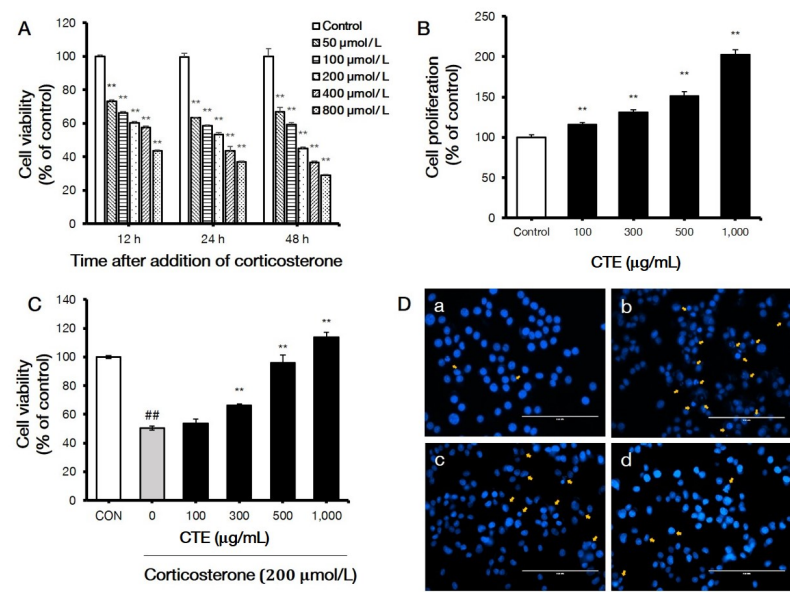

Fig. 1. Effects of corticosterone and CTE on survival in PC12 cells. (A) Concentration- and time-dependent effect of corticosterone. PC12 cells were exposed to various concentrations of corticosterone for 12,24 or 48 hours. (B) Effect of various concentrations of CTE for 24 hours. (C) Effect of various concentrations of CTE on corticosterone-treated cell viability. PC12 cells were exposed to various concentrations of CTE and $200 \mu \mathrm{M}$ corticosterone for 24 hours. Each column represents the mean \pm S.E.M. $(n=5)$. ${ }^{*} P<$ 0.05 and $* * P<0.01$ vs. control group. (D) Representative images of Hoechst 33342 staining. Arrowheads in the pictures indicate nuclei of apoptotic cells (Hoechst-positive cells). Cells were treated with: (a) no drug (control), (b) $200 \mu \mathrm{M}$ corticosterone (200 $\mu \mathrm{M})$; (c) $300 \mu \mathrm{g} / \mathrm{ml}$ CTE plus $200 \mu \mathrm{M}$ corticosterone; or (d) $500 \mu \mathrm{g} / \mathrm{ml}$ CTE plus corticosterone $(200 \mu \mathrm{M})$. Scale bar $=100$ $\mu \mathrm{m}$. CTE: Clematis terniflora extract. that CTE prevents corticosterone-induced cell death in PC12 cells.

\section{Effects of CTE on corticosterone-induced apoptosis of PC12} cells

Morphological analysis of PC12 cells treated with corticosterone revealed the presence of apoptotic bodies in the nucleus (Fig. 1D-b). However, co-treatment with CTE and corticosterone decreased the number of apoptotic bodies in a concentration-dependent manner (Fig. 1D-c, d). These results suggest that CTE significantly decreases the rate of corticosterone-induced apoptosis in PC12 cells.

Effect of CTE on the expression of GRP78, GADD153, and BAD in corticosterone-treated PC12 cells

In general, apoptosis is strongly associated with ER (endoplasmic reticulum) stress. Hence, to further characterize the neuroprotective effect of CTE against corticosteroneinduced apoptosis, we quantified the expression levels of GRP78 (glucose-regulated protein 78) and GADD153 (growth arrest and DNA damage-inducible gene 153), well-known indicators of ER stress. Corticosterone treatment increased the expression levels of GRP78 and GADD153 by $440 \%$ and $260 \%$, respectively, relative to untreated controls (Fig. 2A, B). No significant differences in GRP78 expression were observed
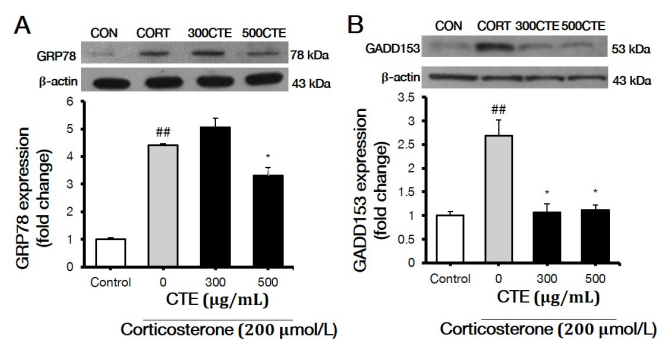

C

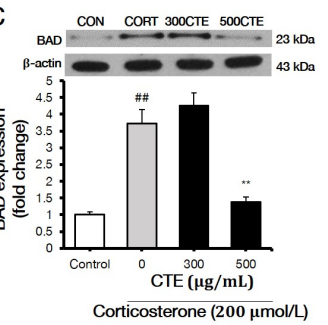

Fig. 2. Effects of CTE on GRP78, GADD153, and BAD expression in corticosterone-treated PC12 cells, as determined by western blot analysis. (A) Expression of GRP78. (B) Expression of GADD153. (C) Expression of BAD. All experiments include control, $200 \mu \mathrm{M}$ corticosterone, $300 \mu \mathrm{g} / \mathrm{ml} \mathrm{CTE}+200 \mu \mathrm{M}$ corticosterone, and $500 \mu \mathrm{g} / \mathrm{ml} \mathrm{CTE}+200 \mu \mathrm{M}$ corticosterone groups. Each column represents the mean \pm S.E.M. $(\mathrm{n}=3)$. ${ }^{\# \#} \mathrm{P}<0.01$ vs. control group; $* P<0.05$ and $* * P<0.01$ vs. corticosterone-treated group. CORT: $200 \mu \mathrm{M}$ corticosterone. 300CTE: $300 \mu \mathrm{g} / \mathrm{ml}$ Clematis terniflora extract plus corticosterone. 500CTE: $500 \mu \mathrm{g} / \mathrm{ml}$ Clematis terniflora extract plus corticosterone. 
upon co-treatment with $300 \mu \mathrm{g} / \mathrm{ml} \mathrm{CTE}$, but GADD153 expression decreased significantly, to a level comparable to that in the control cells. Treatment with $500 \mu \mathrm{g} / \mathrm{ml} \mathrm{CTE}$ decreased GRP78 and GADD153 expression levels by approximately $75 \%$ and $42 \%$ relative to those in corticosterone-treated cells. In addition, to determine the effect of ER stress on the mitochondria, we quantified the expression level of $\mathrm{BAD}$ (BCl-xL/BCl-2-associated death promoter). BAD expression was increased by $347 \%$ relative to that of untreated control by corticosterone treatment, but decreased to the control level upon co-treatment with $500 \mu \mathrm{g} / \mathrm{ml} \mathrm{CTE} \mathrm{(Fig.} \mathrm{2C).}$

\section{Effects of CTE on corticosterone-induced mitochondrial} membrane potential (MMP) in PC12 cells

To confirm that CTE protects against stress-induced mitochondrial malfunction, we investigated alterations in mitochondrial membrane potential (MMP) using the MMP-sensitive dye JC-10. The JC-10 aggregates and emits red fluorescence when MMP is normal, but exists as a monomer and emits green fluorescence when MMP is disrupted. Corticosterone treatment increased the proportion of the green fluorescent monomeric form of JC-10 relative to red fluorescent JC-10 aggregates (Fig. 3). By contrast, the proportion of red fluorescent aggregates increased in a concentration-dependent manner upon co-treatment with CTE. These findings indicate that CTE suppresses corticosteroneinduced stress signals and decreases the disruption of MMP.

Effects of CTE on the expression levels of p-AKT and p-ERK1/2 in corticosterone-treated PC12 cells

Next, we performed a western blot analysis to measure the levels of protein kinase B (AKT) and extracellular signal-

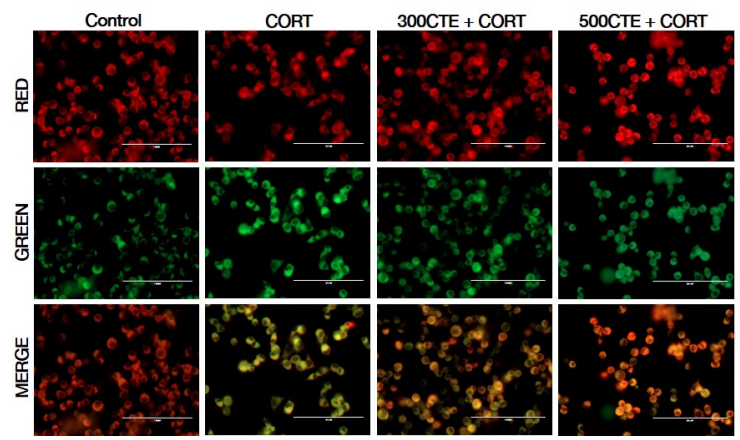

Fig. 3. Effects of CTE on MMP in corticosterone-treated PC12 cells. Representative images of PC12 cells stained with the MMP-sensitive dye JC-10. Red fluorescence is from JC10 aggregates in healthy mitochondria with polarized inner mitochondrial membranes, whereas green fluorescence is emitted by cytosolic JC-10 monomers and indicates MMP dissipation. Merged images indicate co-localization of JC-10 aggregates and monomers. Scale bar $=100 \mu \mathrm{m}$. CORT: $200 \mu \mathrm{M}$ corticosterone. 300CTE: 300 $\mu \mathrm{g} / \mathrm{ml}$ Clematis terniflora extract. 500CTE: $500 \mu \mathrm{g} / \mathrm{ml}$ Clematis terniflora extract. regulated protein kinases 1 and 2 (ERK1/2), which are associated with neuronal cell survival. The phosphorylation of AKT in corticosterone-treated cells was increased by $185 \%$ upon co-treatment with $500 \mu \mathrm{g} / \mathrm{ml}$ CTE (Fig. 4A). Treatment with 300 and $500 \mu \mathrm{g} / \mathrm{ml}$ CTE increased phosphorylation of ERK $1 / 2$ by approximately $335 \%$ and $330 \%$, respectively, relative to the corticosterone-treated group (Fig. 4B).

\section{DISCUSSION}

Chronic stress can damage the central nervous system (15), largely via the activity of corticosterone, which is secreted by the adrenal glands in response to stress. In this study, we found that apoptotic cell death was induced in PC12 cells by corticosterone in a concentration- and time-dependent manner, and we firstly demonstrated that CTE protects PC12 cells against apoptosis under stressful conditions.

Our findings indicate that corticosterone, in conjunction with ER stress and mitochondrial malfunction, induces apoptotic neuronal cell death. ER stress is an important trigger of the apoptotic process in neuronal cells $(16,17)$. ER stressassociated membrane damage can result in mitochondrial malfunction via multiple mechanisms, which can in turn induce apoptosis (18). We found that the expression levels of ER stress markers (GRP78 and GADD153) increased by the presence of the stress factor corticosterone. But the expression levels significantly decreased by co-treatment with CTE, which also prevented mitochondrial malfunction. Furthermore, the corticosterone-associated reductions in the phosphorylation levels of AKT and ERK1/2 were dramatically reversed by CTE. Phosphorylation of AKT and ERK1/2 increases neuronal survival by decreasing the initial ER stress that occurs during
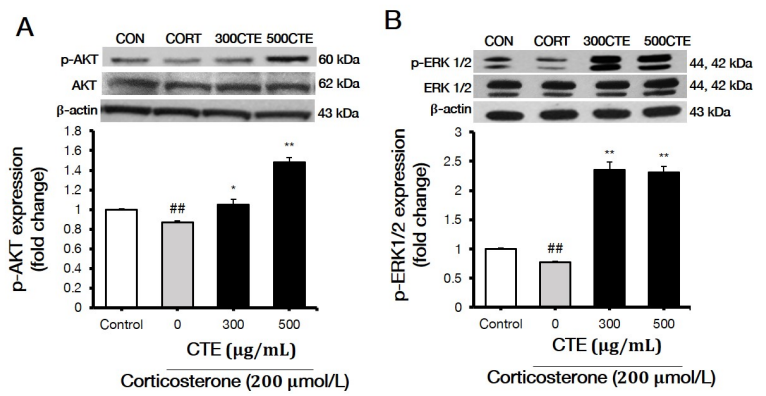

Fig. 4. Effects of CTE on p-AKT and $p$-ERK $1 / 2$ expression in corticosterone-treated $\mathrm{PC} 12$ cells, as determined by western blot analysis. (A) Expression of p-AKT and AKT. (B) Expression of p-ERK1/2 and ERK1/2. All experiments include control, $200 \mu \mathrm{M}$ corticosterone, $300 \mu \mathrm{g} / \mathrm{ml} \mathrm{CTE}+200 \mu \mathrm{M}$ corticosterone, and $500 \mu \mathrm{g} / \mathrm{ml}$ CTE $+200 \mu \mathrm{M}$ corticosterone groups. Each column represents the mean \pm S.E.M. $(n=3)$. ${ }^{\# \# P}<0.01$ vs. control group; $* P<0.05$ and $* * P<0.01$ vs. corticosterone-treated group. CORT: $200 \mu \mathrm{M}$ corticosterone. 300CTE: $300 \mu \mathrm{g} / \mathrm{ml}$ Clematis terniflora extract plus corticosterone. 500CTE: $500 \mu \mathrm{g} / \mathrm{ml}$ Clematis terniflora extract plus corticosterone. 
apoptosis in the various types of neurons (19-21). Thus, CTE protects against neuronal apoptosis by effectively blocking both the initial ER stress and the mitochondrial malfunction caused by stress factors.

GRP78 is upregulated during the early stages of the ER stress response, and is an important indicator of ER stress (22). Interestingly, CTE-induced changes in phosphorylation of AKT and BAD expression similar to those in GRP78 expression. Based on our findings, these proteins are likely to be intimately involved in the protective effect of CTE against stress-induced neuronal apoptosis. Multiple reports show that increases in ER stress and BAD expression initiate neuronal apoptosis by inducing mitochondrial malfunction (23, 24). Furthermore, activation of AKT generally protects neurons against apoptosis by suppressing ER stress and BAD expression $(25,26)$. Thus, the concentration-dependent cellular protective effect of CTE is likely associated with alterations in GRP78, p-AKT, and BAD expression levels. Further investigation is required to identify the specific mechanisms underlying this effect.

Upon CTE treatment, the expression pattern of GADD153, another ER stress marker, differed from that of GRP78. In contrast to GRP78, GADD153 promotes apoptosis under ER stressed conditions $(27,28)$. Consequently, to protect neurons against ER stress-induced apoptosis, it is essential to inhibit GADD153 expression. Moreover, the alterations in the phosphorylation state of ERK $1 / 2$ were comparable to those in expression of GADD153. Activation of ERK1/2 is associated with protection against apoptosis, and is required specifically to suppress the ER stress response (29-32). Thus, CTE treatment, coupled with ERK1/2 activation and GADD153 downregulation, inhibits corticosterone-induced neuronal cell death.

In conclusion, our findings indicate that CTE protects neurons against corticosterone-induced apoptosis. The molecular mechanism underlying this effect involves protection of the ER associated with the activation of AKT and ERK1/2, along with downstream inhibition of mitochondrial damage. Also, we proved that CTE has no intrinsic toxicity in neuronal cells. Therefore, we consider CTE as a possible anti-stress health supplement and naturally derived medicinal substance that could ameliorate neural damage caused by chronic stress.

\section{MATERIALS AND METHODS}

\section{Preparation of CTE}

C. terniflora was obtained from Eumseong-gun, Chungcheongbuk-do, Republic of Korea. Dried C. terniflora (5 kg) was extracted with $50 \%$ ethanol at $80^{\circ} \mathrm{C}$, three times for 3 hours each, on a reflux extractor. The ethanol extracts were combined and filtered through Whatman No.2 filter paper, and then evaporated at $60^{\circ} \mathrm{C}$ in an R-3000 vacuum rotary evaporator (Büchi Labortechnik AG, Flawil, Switzerland). Powdered CTE was produced by freeze-drying the concentrate in an FD8505 freeze-dryer (Ilshin Lab Co., Seoul, Korea).

\section{Cell culture and treatment}

PC12 cells were obtained from the Korean Cell Line Bank (Seoul, Korea) and maintained in RPMI 1640 medium supplemented with $10 \%$ FBS (fetal bovine serum) and $1 \%$ antibiotic-antimycotic at $37^{\circ} \mathrm{C}$ in a humidified atmosphere of $95 \%$ air and $5 \% \mathrm{CO}_{2}$. Twenty-four hours after the cells were seeded, the medium was refreshed with RPMI 1640 containing $1 \%$ FBS.

Corticosterone was dissolved in DMSO, and different concentrations of corticosterone $(50,100,200,400$, or 800 $\mu \mathrm{M})$ were added for 12,24 , or 48 hours to determine the appropriate concentration for cell damage. The final concentration of DMSO was less than $0.1 \%(\mathrm{v} / \mathrm{v})$. To study the neuroprotective effect of CTE, PC12 cells were divided into the following groups: non-treated controls, corticosterone (200 $\mu \mathrm{M})$-treated, and CTE (300 or $500 \mu \mathrm{g} / \mathrm{ml}$ ) plus corticosterone $(200 \mu \mathrm{M})$-treated. CTE was added for 24 hours prior to treatment with corticosterone $(200 \mu \mathrm{M})$.

\section{Determination of cell viability}

Cytotoxicity of corticosterone was determined using the EZ-Cytox kit (Daeil Lab, Seoul, Korea). PC12 cells were seeded at a density of $5 \times 10^{4}$ cells/well in 96-well microplates. At the end of the treatment, the PC12 cells were co-incubated with $20 \mathrm{ml}$ of EZ-Cytox solution for 2 hours in darkness, and the absorbance at $450 \mathrm{~nm}$ of each well was measured using an Infinite M200 PRO NanoQuant microplate reader (TECAN, Zurich, Switzerland). Cell viability was expressed as a percentage of the value in the non-treated control group.

\section{Hoechst 33342 staining}

Hoechst 33342 staining was used to distinguish apoptotic from normal cells based on nuclear chromatin condensation and fragmentation. PC12 cells were seeded into $35 \mathrm{~mm}$ dishes at $4 \times 10^{5}$ cells/dish. After treatment, the cells were incubated with $5 \mu \mathrm{g} / \mathrm{ml}$ Hoechst 33342 for 5 minutes, washed twice with phosphate-buffered saline (PBS), and observed on an EVOS FL Imaging System (Life Technologies, Carlsbad, CA, USA).

\section{Assessment of MMP}

Changes in MMP were assessed using the Mitochondria Membrane Potential Kit (Sigma-Aldrich, St. Louis, MO, USA). PC12 cells were seeded into $35 \mathrm{~mm}$ dishes at a density of $4 \times$ $10^{5}$ cells/dish. After treatments, the cells were loaded with JC-10 solution and incubated for 30 minutes in the dark. Buffer $\mathrm{B}$ was added, and the cells were observed on an EVOS FL Imaging System.

\section{Westem blot analysis}

After treatments, PC12 cells were harvested, and washed once with PBS, and then lysed with cell lysis buffer containing 1 $\mathrm{mM}$ PMSF (phenylmethylsulfonylfluoride) and a $1 \%$ protease 
inhibitor cocktail. Whole cell lysates were centrifuged at $16,022 \mathrm{xg}$ for 10 minutes at $4^{\circ} \mathrm{C}$, and the supernatants were collected. Concentrations were determined by bicinchoninic acid assay. Equal amounts of protein $(20 \mu \mathrm{g})$ were separated by electrophoresis on $4-12 \%$ sodium dodecyl sulfate-polyacrylamide gels and transferred to Duralon-UV membranes (Stratagene, La Jolla, CA, USA). These membranes were incubated with 5\% $(\mathrm{w} / \mathrm{v})$ non-fat milk powder in Tris-buffered saline solution containing $0.1 \%(\mathrm{v} / \mathrm{v})$ Tween-20 (TBST) for 1 hour to block nonspecific binding sites. The membranes were then incubated overnight at $4^{\circ} \mathrm{C}$ with the following primary antibodies: $\beta$-actin (1:1000; ab8226), GRP78 (1:1000; sc-13968), GADD153 (1:1000; sc-793), BAD (1:1000; ab32445), p-ERK1/2 (1:1000; ab214362), ERK1/2 (1:1000; ab196883), p-AKT (1:1000; ab38449) and AKT (1:1000; ab8805). After washing three times with TBST, the membranes were incubated with secondary antibodies (goat anti-rabbit IgG-FITC, 1:10000; sc-2012) for 90 minutes at room temperature. Blots were developed using SuperSignal ${ }^{(\mathbb{R}}$ West Pico Chemiluminescent Substrate (Thermo Fisher Scientific, Waltham, MA, USA).

\section{Statistical analysis}

The results are presented as means \pm standard error of measurement (S.E.M). One-way analysis of variance (ANOVA) was used to assess differences between groups. Differences were considered to be statistically significant at a $\mathrm{P}$ value of $\mathrm{P}<$ 0.05 .

\section{ACKNOWLEDGEMENTS}

This research was supported by the Agriculture, Food and Rural Affairs Research Center Support Program, Ministry of Agriculture, Food and Rural Affairs, under Grant 714001-07.

\section{CONFLICTS OF INTEREST}

The authors have no conflicting interests.

\section{REFERENCES}

1. Cella DF and Tulsky DS (1990) Measuring quality of life today: methodological aspects. Oncology (Williston Park) 4, 29-38

2. Carlson LE, Speca M, Patel KD and Goodey E (2003) Mindfulness-based stress reduction in relation to quality of life, mood, symptoms of stress, and immune parameters in breast and prostate cancer outpatients. Psychosom Med 65, 571-581

3. McEwen BS and Stellar E (1993) Stress and the individual. Mechanisms leading to disease. Arch Intern Med 153, 2093-2101

4. Mizoguchi K, Kunishita T, Chui DH and Tabira T (1992) Stress induces neuronal death in the hippocampus of castrated rats. Neurosci Lett 138, 157-160
5. Kendler KS, Karkowski LM and Prescott CA (1999) Causal relationship between stressful life events and the onset of major depression. Am J Psychiatry 156, 837-841

6. Lindauer RJ (2002) Post-traumatic stress disorder. N Engl J Med 346, 1495-1498

7. Martin LJ, Pan Y, Price AC et al (2006) Parkinson's disease alpha-synuclein transgenic mice develop neuronal mitochondrial degeneration and cell death. J Neurosci 26, 41-50

8. Yang Y, Mufson EJ and Herrup K (2003) Neuronal cell death is preceded by cell cycle events at all stages of Alzheimer's disease. J Neurosci 23, 2557-2563

9. Petty F, Trivedi MH, Fulton M and Rush AJ (1995) Benzodiazepines as antidepressants: does GABA play a role in depression? Biol Psychiatry 38, 578-591

10. Greenblatt DJ and Shader RI (1978) Dependence, tolerance, and addiction to benzodiazepines: clinical and pharmacokinetic considerations. Drug Metab Rev 8, 13-28

11. Longo LP and Johnson B (2000) Addiction: Part I. Benzodiazepines--side effects, abuse risk and alternatives. Am Fam Physician 61, 2121-2128

12. Liu XB, Yang BX, Zhang L, Lu YZ, Gong MH and Tian JK (2015) An in vivo and in vitro assessment of the anti-inflammatory, antinociceptive, and immunomodulatory activities of Clematis terniflora DC. extract, participation of aurantiamide acetate. J Ethnopharmacol 169, 287-294

13. Chen RZ, Cui L, Guo YJ et al (2011) In vivo study of four preparative extracts of Clematis terniflora DC. for antinociceptive activity and anti-inflammatory activity in rat model of carrageenan-induced chronic non-bacterial prostatitis. J Ethnopharmacol 134, 1018-1023

14. Tsigos C and Chrousos GP (2002) Hypothalamicpituitary-adrenal axis, neuroendocrine factors and stress. J Psychosom Res 53, 865-871

15. Olivenza R, Moro MA, Lizasoain I et al (2000) Chronic stress induces the expression of inducible nitric oxide synthase in rat brain cortex. J Neurochem 74, 785-791

16. Puthalakath $H, O^{\prime}$ Reilly LA, Gunn P et al (2007) ER stress triggers apoptosis by activating $\mathrm{BH} 3$-only protein Bim. Cell 129, 1337-1349

17. Tabas I and Ron D (2011) Integrating the mechanisms of apoptosis induced by endoplasmic reticulum stress. Nat Cell Biol 13, 184-190

18. Reimertz C, Kogel D, Rami A, Chittenden T and Prehn JH (2003) Gene expression during ER stress-induced apoptosis in neurons: induction of the $\mathrm{BH}$-only protein Bbc3/PUMA and activation of the mitochondrial apoptosis pathway. J Cell Biol 162, 587-597

19. Arai K, Lee SR, van Leyen K, Kurose H and Lo EH (2004) Involvement of ERK MAP kinase in endoplasmic reticulum stress in SH-SY5Y human neuroblastoma cells. J Neurochem 89, 232-239

20. Yuan Y, Guo Q, Ye Z, Pingping X, Wang N and Song Z (2011) Ischemic postconditioning protects brain from ischemia/reperfusion injury by attenuating endoplasmic reticulum stress-induced apoptosis through Pl3K-Akt pathway. Brain Res 1367, 85-93

21. Yang SJ, Kim J, Lee SE, Ahn JY, Choi SY, Cho SW (2017) Anti-inflammatory and anti-oxidative effects of 3-(naph- 
thalen-2-yl(propoxy)methyl)azetidine hydrochloride on $\beta$-amyloid-induced microglial activation. BMB Rep 50, 634-639

22. Hoozemans JJ, van Haastert ES, Nijholt DA, Rozemuller AJ and Scheper W (2012) Activation of the unfolded protein response is an early event in Alzheimer's and Parkinson's disease. Neurodegener Dis 10, 212-215

23. Takuma K, Yan SS, Stern DM and Yamada K (2005) Mitochondrial dysfunction, endoplasmic reticulum stress, and apoptosis in Alzheimer's disease. J Pharmacol Sci 97, 312-316

24. Wang HG, Pathan N, Ethell IM et al (1999) $\mathrm{Ca}^{2+}$ - induced apoptosis through calcineurin dephosphorylation of BAD. Science 284, 339-343

25. Kamada H, Nito C, Endo $\mathrm{H}$ and Chan PH (2007) Bad as a converging signaling molecule between survival PI3-K/Akt and death JNK in neurons after transient focal cerebral ischemia in rats. J Cereb Blood Flow Metab 27, 521-533

26. Hu P, Han Z, Couvillon AD and Exton JH (2004) Critical role of endogenous Akt/IAPs and MEK1/ERK pathways in counteracting endoplasmic reticulum stress-induced cell death. J Biol Chem 279, 49420-49429

27. Matsumoto M, Minami M, Takeda K, Sakao $Y$ and Akira S (1996) Ectopic expression of CHOP (GADD153) induces apoptosis in M1 myeloblastic leukemia cells. FEBS Lett 395, 143-147

28. Maytin EV, Ubeda M, Lin JC and Habener JF (2001) Stress-inducible transcription factor $\mathrm{CHOP} /$ gadd153 induces apoptosis in mammalian cells via p38 kinase-dependent and -independent mechanisms. Exp Cell Res 267, 193-204

29. Spencer JP, Rice-Evans C and Williams RJ (2003) Modulation of pro-survival Akt/protein kinase $B$ and ERK1/2 signaling cascades by quercetin and its in vivo metabolites underlie their action on neuronal viability. J Biol Chem 278, 34783-34793

30. Vauzour D, Vafeiadou K, Rice-Evans C, Williams RJ and Spencer JP (2007) Activation of pro-survival Akt and ERK1/2 signalling pathways underlie the anti-apoptotic effects of flavanones in cortical neurons. J Neurochem 103, 1355-1367

31. Wang Z, Zhang H, Xu X et al (2012) bFGF inhibits ER stress induced by ischemic oxidative injury via activation of the PI3K/Akt and ERK1/2 pathways. Toxicol Lett 212, $137-146$

32. Ryoo HD, Vasudevan D (2017) Two distinct nodes of translational inhibition in the integrated Stress Response. BMB Rep 50, 539-545 